\title{
Cigarette smoking in adolescents with asthma in Jordan: I mpact of peer-led education in high schools
}

\author{
Nihaya Al-sheyab ${ }^{1}$, Robyn Gallagher ${ }^{2}$, Patrick Gallagher ${ }^{2}$, Smita Shah ${ }^{3}$ \\ 1. Faculty of Nursing, Department of Maternal and Child Health, Jordan University of Science and Technology, Irbid, \\ Jordan. 2. Faculty of Nursing, Midwifery and Health, University of Technology, Sydney, Australia. 3. Faculty of Medicine, \\ University of Sydney and Director, Primary Health Care Education and Research Unit, Western Sydney Local Health District, \\ Sydney, Australia
}

Correspondence: Nihaya Al-sheyab. Address: Faculty of Nursing, Department of Maternal and Child Health, Jordan University of Science and Technology, Irbid, Jordan. Email: jood1965@yahoo.com.

Received: November 18, 2012

Accepted: January 3, 2013

Online Published: February 25, 2013

DOI : $10.5430 /$ jnep.v3n9p13

URL: http://dx.doi.org/10.5430/jnep.v3n9p13

\section{Abstract}

Background: Peer-led smoking prevention programs focus on teaching adolescents—especially those with asthma- who are affected most by cigarettes, refusal skills to lower their intention to smoke. The purpose of this study was to determine the impact of a peer-led asthma education program on students who were smokers in terms of self-efficacy to resist smoking, asthma knowledge and asthma-related quality of life.

Methods: This study is a secondary analysis of a cluster-randomized controlled trial of students with asthma $(n=259)$ in 4 randomly-selected high schools, stratified for gender in Northern Jordan, using a closed-envelope technique. Trained bilingual health workers facilitated the implementation of the peer-led program, which uses a three-step cascade process to train peers from year 11 and 10 over a three week period to deliver asthma education for the school community, with the aid of well-established resources. Students with asthma $(n=261)$ in grades 8,9 and 10 were surveyed at baseline in December 2006 and three months post-intervention on the main outcomes, which were asthma-related quality of life, knowledge of asthma management, and self-efficacy to resist smoking. For the purpose of this paper, we assessed the impact on the intervention only on students who were smokers $(n=72)$.

Results: The prevalence of smoking among students with asthma was $29 \%$. Male students (44\%) were more likely to smoke than females (6\%) $(p<0.001)$. Compared to the control group, the peer-led intervention improved self-efficacy to resist smoking, understand asthma and asthma-related quality of life. Smokers within the intervention schools improved their self-efficacy to resist smoking by $83 \%(p=0.001)$, asthma knowledge by $60 \%(p=0.001)$ and demonstrated benefits within all the sub-domains of asthma related quality of life when compared to controls ( $p=0.001)$.

Conclusion: The prevalence of smoking among high school Jordanian students with asthma, especially males, is alarmingly high, highlighting the need for early intervention. A school-based peer-led asthma and smoking education approach can be effective in motivating students to not smoke. Therefore, nurse educators worldwide, especially who work in youth centers, community, and school health fields, need to be aware of the effectiveness, availability, and possible adoption of such innovative interventions in order to improve overall well-being for adolescents in general and for smokers in specific. 


\section{Key words}

Adolescents, Smoking, Self-efficacy, Asthma, Peer education

\section{I ntroduction}

Cigarette smoking is a serious and risky health-related behaviour usually taken up in adolescence and then continuing into adulthood $^{[1]}$.

The World Health Organization (WHO) approximates that there are more than one billion smokers worldwide and that more than $80 \%$ of them live in low and middle-income countries ${ }^{[2]}$. The estimated prevalence of ever smoking among Jordanian youth is ranged from 18\% in 1999 to about 13\% in 2004 and $16 \%$ in 2007, whereas the prevalence was substantially greater among boys than girls ${ }^{[3]}$. Also, the prevalence of current smoking among university students in Jordan was $35.0 \%$ (56.9\% for males and $11.4 \%$ for females), with about $80 \%$ were cigarettes smokers ${ }^{[4]}$.

Nicotine dependence may begin with exposure to low levels of nicotine in early adolescence ${ }^{[5]}$. Smoking is particularly problematic for adolescents who have asthma because this subgroup is more likely to have more severe asthma ${ }^{[6-10]}$. Smoking is reported to double the risk of dying amongst adolescents with asthma ${ }^{[11]}$. The detrimental effect of smoking on outcomes is due in part to decreased adherence to controller medications noted in this population ${ }^{[12]}$. Therefore, any smoking prevention program should address asthma-related issues as well.

Peer influence is an important factor in the development of adolescent smoking behaviour and has been associated with higher smoking rates and lower self-efficacy to stop smoking in adolescents with asthma ${ }^{[6]}$. On the other hand, peers can also positively influence adolescent smokers to quit this behavior ${ }^{[13]}$ and increase awareness about the adverse health-related outcomes of smoking. Peer-led smoking prevention programs focus on teaching adolescents refusal skills to lower their intention to smoke ${ }^{[7,9,14]}$. While these interventions show promise, at least on the short term ${ }^{[15]}$, few have been designed or tested in the Middle East, where smoking is prevalent and there are a lack of adolescent smoking prevention programs ${ }^{[16]}$. However, a very effective peer education program that was designed to reduce smoking prevalence among high school adolescents named the 'ASSIST' (A Stop Smoking in School Trial) program ${ }^{[17]}$. A total of 10,730 year 8 students was recruited from 59 high schools in England, 835 of whom consented to be trained as peer supporters. In this study, peer supporters were nominated by their peers, thereby ensuring that the most influential members of several peer groups were involved ${ }^{[17]}$. At 12 months post intervention, the smoking prevalence among occasional smokers in the intervention schools was $18.2 \%$ lower than in the control schools and non smokers' determination not to smoke was reinforced, and this implies the sustainability of such programs. Therefore, Effective anti-tobacco peer education programmes targeting youth, must be implemented more widely in Jordan ${ }^{[3]}$.

The Adolescent Asthma Action (Triple A) program (http://triplea.asthma.org.au) offers a solution ${ }^{[18]}$. The Triple A is a peer-led, school-based intervention program, directed at improving asthma self-management and reducing the uptake of smoking amongst adolescents. This program has been shown to improve quality of life for adolescents with asthma, increase asthma knowledge and decrease asthma-related school absenteeism in Australia. The program has also been tested in Jordan where it is known as the Triple A in Jordan (TAJ) and resulted in significant improvement in self-efficacy to resist smoking ${ }^{[19,20]}$. However, to the researchers' knowledge, there were no similar studies that examined the impact of school-based, peer-led intervention on adolescent smoking behaviour in Jordan.

The purpose of this study was to determine the impact of TAJ on the subgroup of students who smoked on the outcomes of self-efficacy to resist smoking, asthma knowledge and asthma-related quality of life. 


\section{Materials and methods}

\subsection{Participants}

This study is a secondary analysis of a cluster-randomized controlled trial of Triple A in Jordan. The methods have been described elsewhere but are summarised here ${ }^{[19]}$. Adolescents were recruited from four high schools in the Irbid region of Jordan. These schools were stratified by gender (two schools each for boys and girls) to ensure a balanced sample, as gender-specific outcomes were expected. All selected schools agreed to participate in the study. Ethics approval was granted by the Human Research Committees of the Ministry of Education for Jordan, the relevant Irbid school districts, and the University of Technology, Sydney, Australia.

Students were considered eligible to participate in the study if they were enrolled in either grade 8, class 9, or class 10 and had reported wheezing in the last 12 months, as identified by the Arabic version of the International Study for Asthma and Allergy in Childhood (ISAAC) written questionnaire (described later in this study); were capable of completing the survey; were literate and conversant in both Arabic and English; regularly attended school; absences do not exceed a month per academic year; were free of other major diseases with the potential to impact quality of life measures; and were not involved in another health-related study.

\subsection{Measures}

Adolescents completed self-report questionnaires at school at baseline and three months later. All questionnaires were written in Arabic. Data related to smoking were collected using a checklist developed by the researchers during the pilot phase ${ }^{[20]}$ on whether they smoked and as well as who smoked in their family. In addition data on demographics, asthma diagnosis and medications taken were also collected.

Asthma symptom severity: Symptoms were assessed at baseline using the Arabic version of the ISAAC written questionnaire, a tool developed to reliably identify children likely to have asthma at young ages and internationally by taking a symptomatic, not diagnostic, approach ${ }^{[21]}$. The ISAAC written questionnaire was reported to be valid ${ }^{[22,23]}$.

Self-efficacy to resist smoking: The Self-Administered Nicotine Dependence Scale (SANDS) measures self-efficacy to resist smoking, and includes 16 items, 10 items for self-efficacy and 6 for loss of control in relation to smoking. Scores are added together for a total ranging from 0 to $16^{[24]}$. Higher scores reflect more capacity to resist smoking. The SANDS was reliable in our study, with a Cronbach's alpha of 0.81 . The SANDS was reported to be reliable in previous studies too ${ }^{\text {[25] }}$.

Knowledge of asthma self-management: The Arabic version of the Asthma Knowledge Consumer Questionnaire (AKCQ) assesses knowledge of asthma management and asthma medication using 12 true/false items, and was reported to be valid and reliable ${ }^{[26]}$. The scores are summed for a total between 0 (no correct answers) to 12 (all answers correct). The reliability of the AKCQ in our study was relatively low (Cronbach's alpha $=0.44$ ) in comparison to the 0.78 noted in the development/validation study.

Asthma-related quality of life: The Arabic version of the Paediatric Asthma Quality of Life Questionnaire (PAQLQ) contains 23 items and addresses the subdomains of symptoms (10 items), activity limitations (5 items), and emotional function (8 items) ${ }^{[27]}$. Participants respond using a 7-point Likert scale. The mean is taken of the total responses of each domain, and then the mean is taken of all three domain scores to produce the overall score. Scores vary from 1 (full impairment) to 7 (no impairment). A change of 0.5 within any domain or in the overall score is considered a minimally significant effect, a change of 1.0 being a moderate change, and any change of 1.5 or more is a clinically meaningful change. The PAQLQ has been reported to be valid for both evaluative and discriminative purposes and a reliable tool ${ }^{[28]}$. The PAQLQ proved reliable in our study, with a Cronbach's alpha of 0.97 at baseline and outcome. 
Possible confounding variables to the study intervention including the impact of relative media and teachers had not been controlled for during the time of the implementation and the data collection process. However, equal possible effect, if any, was assumed on both the control and the intervention groups.

\subsection{Study intervention}

The intervention is based on the Triple A program, an evidence-based peer-led program based on empowerment education in high schools ${ }^{[29]}$. The content of the Peer Leader Training Program was delivered by bilingual Jordanian health workers, in both English and Arabic and has been described previously ${ }^{[19]}$. Twenty four peer leaders from year 11 were trained by these health workers to deliver the three Triple A lessons to the year 10 students. The year 10 students then prepared and presented a series of skits to year 8 and 9 students, with content designed to improve self-efficacy to resist smoking, self-management of asthma symptoms, and the school culture towards asthma.

\subsection{Data analysis}

The required sample size $(n=250)$ was calculated for the original study to detect a clinically meaningful difference in the PAQLQ, with a power of $80 \%$, alpha of 0.05 and an intra-class correlation coefficient (ICC) of less than 0.01 to account for potential clustering effects. Cluster randomisation at the school level was employed to allocate groups, using the closed envelope technique stratified for the gender at the school (2 each).

Data were analysed using the Statistical Package for the Social Sciences (SPSS v 19). Means, frequencies, and percentages were used to describe the results. Chi-square tests were used to compare groups at baseline on categorical variables. Independent sample $t$ test was used to compare the control and the intervention groups at baseline and outcome on continuous variables. Paired sample $t$ test was also used to compare the within group difference over time.

\section{Results}

\subsection{Sample characteristics}

Table 1 describes the characteristics of smokers versus nonsmokers. The sample included more males (53\%) than females (43\%). Most students were in year 8 of school (43\%) and reported mild asthma (69\%).

\subsection{Smoking behaviour}

Twenty-nine percent of the students reported smoking (see Table 1). Students who smoked were significantly more likely to be male ( $44 \%$ of males versus $6 \%$ of females) and to have family members who smoked ( $32 \%$ had family who smoked versus $16 \%$ with no family who smoked). There were no differences between smokers and nonsmokers for year at school, severity of asthma or frequency of family smoking.

\subsection{I mpact of TAJ}

The impact of TAJ was assessed in smokers $(n=72)$. At baseline in the smokers, the TAJ and control groups were equivalent for gender, year of school, asthma severity, sub-domains and total health related quality of life (see Table 2). However, the control group had significantly higher self-efficacy to resist smoking (MD 1.38, $p=.007$ ) and asthma knowledge (MD 1.08, $p=.009$ ). At three months follow up participants in the TAJ had overcome these differences to have significantly better scores on all outcomes measured. Smokers in the TAJ group had improved their self-efficacy to resist smoking by $83 \%$ from baseline to have 4.37 points more self-efficacy to resist smoking than controls. TAJ participants also improved their asthma knowledge by $60 \%$ from baseline resulting in a mean difference of 2.31 points compared to the controls (see Figure 1 and 2). The TAJ participants demonstrated benefits, classified as moderate, in all sub-domains of health related quality of life in comparison to controls. 
Table 1. Baseline characteristics compared for smokers versus non-smokers

\begin{tabular}{|c|c|c|c|}
\hline \multirow{2}{*}{ Characteristic } & Smokers(n= 72) & Non-smokers $(n=187)$ & \multirow{2}{*}{ p- level* } \\
\hline & $\mathbf{n}(\%)$ & $\mathrm{n}(\%)$ & \\
\hline \multicolumn{4}{|l|}{ Gender } \\
\hline Males & $65(44)$ & $83(56)$ & \multirow{2}{*}{$<.001$} \\
\hline Females & $7(6)$ & $104(92)$ & \\
\hline \multicolumn{4}{|l|}{ Class level } \\
\hline Year 8 & $37(33)$ & 75 (67) & \multirow{3}{*}{0.12} \\
\hline Year 9 & $16(20)$ & $65(80)$ & \\
\hline Year 10 & $19(29)$ & $47(71)$ & \\
\hline \multicolumn{4}{|c|}{ No. wheezing attacks } \\
\hline 1-3/year & $49(26)$ & $142(74)$ & \multirow{3}{*}{0.18} \\
\hline 4-12/year & $11(31)$ & $24(69)$ & \\
\hline >12/year & $5(29)$ & $12(71)$ & \\
\hline \multicolumn{4}{|c|}{ Asthma diagnosed by physician } \\
\hline Yes & $48(26)$ & $135(74)$ & \multirow{2}{*}{0.46} \\
\hline No & $23(31)$ & 52 (69) & \\
\hline \multicolumn{4}{|c|}{ Family members smoke } \\
\hline Yes & $59(32)$ & $123(68)$ & \multirow{2}{*}{0.009} \\
\hline No & $12(16)$ & $62(84)$ & \\
\hline \multicolumn{4}{|c|}{ Frequency of family smoking } \\
\hline Lightly & $5(17)$ & $25(83)$ & \multirow{2}{*}{0.07} \\
\hline Heavily & $58(33)$ & $117(67)$ & \\
\hline
\end{tabular}

*T-test or chi-squared test used according to the level of the variable

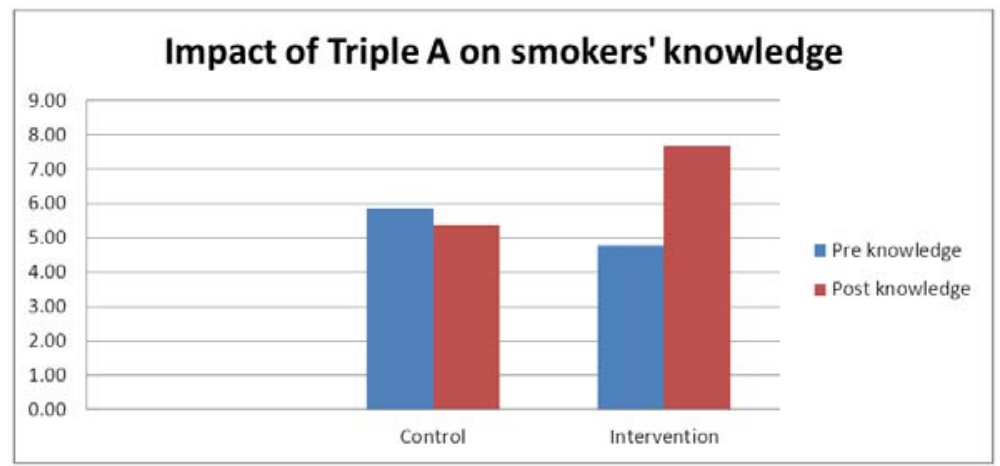

Figure 1. Impact of the intervention on asthma related knowledge for adolescents with asthma who smoke (N=72).

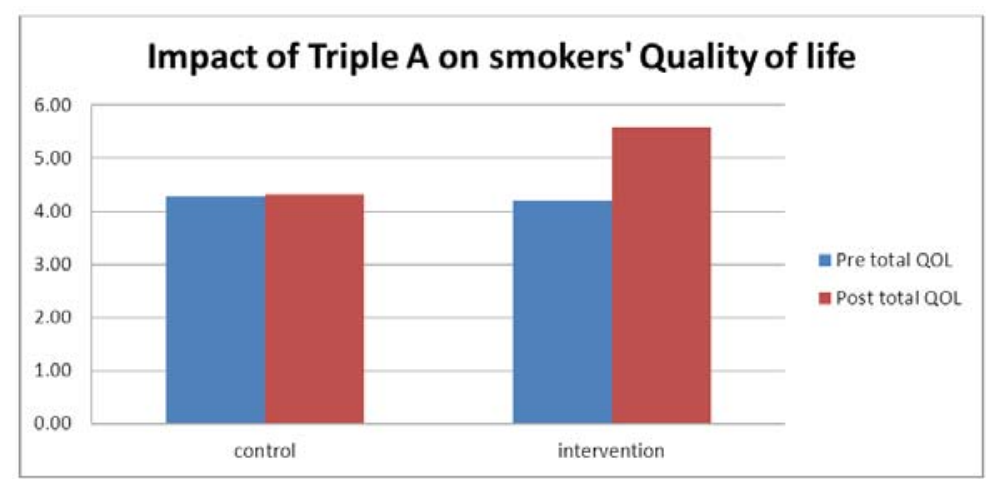

Figure 2. Impact of the intervention on asthma related quality of life for adolescents with asthma who smoke (N=72) Published by Sciedu Press 


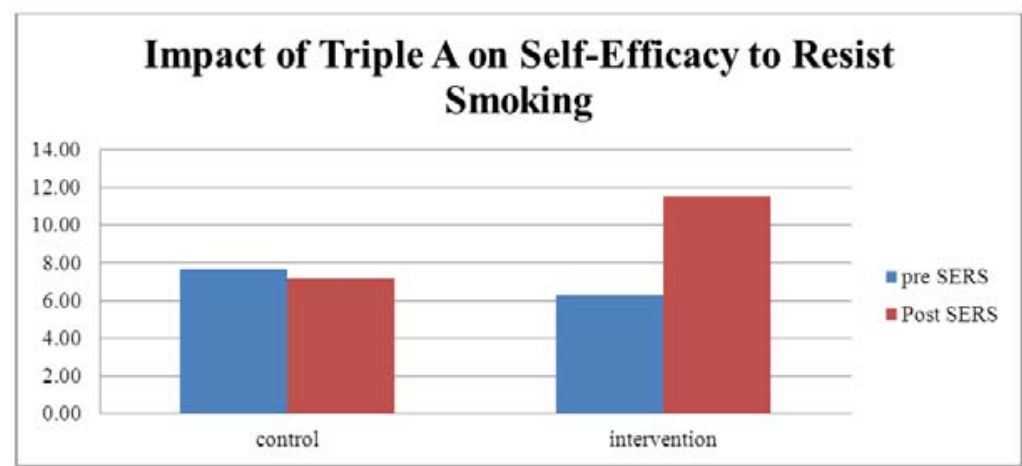

Figure 3. Impact of the intervention on self efficacy to resist smoking for adolescents with asthma who smoke (N=72)

Table 2. Self-efficacy to resist smoking, asthma knowledge and quality of life TAJ versus Control at baseline and outcome

\begin{tabular}{|c|c|c|c|c|c|c|c|c|}
\hline \multirow{3}{*}{ Characteristic \pm} & $\begin{array}{l}\text { Control } \\
(\mathrm{n}=39)\end{array}$ & $\begin{array}{l}\text { TAJ } \\
(\mathbf{n}=33)\end{array}$ & $\begin{array}{l}\text { Mean } \\
\text { Difference }\end{array}$ & \multirow[t]{2}{*}{$p$-level* } & $\begin{array}{l}\text { Control } \\
(\mathrm{n}=39)\end{array}$ & $\begin{array}{l}\text { TAJ } \\
(\mathbf{n}=33)\end{array}$ & $\begin{array}{l}\text { Mean } \\
\text { Difference } \\
\end{array}$ & \multirow[t]{2}{*}{$p$-level* } \\
\hline & M (SD) & M (SD) & MD & & M (SD) & M (SD) & MD & \\
\hline & \multicolumn{4}{|l|}{ BASELINE } & \multicolumn{4}{|l|}{ OUTCOME } \\
\hline $\begin{array}{l}\text { Self-efficacy to resist } \\
\text { smoking } \\
\text { (potential range 0-16) }\end{array}$ & $7.67(2.1)$ & $6.29(1.86)$ & -1.38 & 0.007 & 7.16 (3.28) & $11.53(2.08)$ & 4.37 & $<.001$ \\
\hline $\begin{array}{l}\text { Asthma knowledge } \\
\text { (potential range 0-12) }\end{array}$ & 5.87 (1.59) & $4.79(1.81)$ & -1.08 & 0.009 & $5.36(2.09)$ & 7.67 (2.19) & 2.31 & $<.001$ \\
\hline \multicolumn{9}{|l|}{$\begin{array}{l}\text { Health Related Quality } \\
\text { of Life }\end{array}$} \\
\hline Activity domain & $4.22(1.36)$ & $4.53(1.49)$ & 0.31 & 0.30 & $4.16(1.50)$ & $5.51(1.53)$ & 1.35 & $<.001$ \\
\hline Symptoms domain & $4.23(1.24)$ & 3.89 (1.23) & -0.55 & 0.20 & $4.32(1.47)$ & 5.48 (1.39) & 1.16 & $<.001$ \\
\hline Emotional domain & $4.44(1.45)$ & $4.26(1.42)$ & -0.18 & 0.60 & $4.48(1.45)$ & $5.74(1.34)$ & 1.26 & $<.001$ \\
\hline $\begin{array}{l}\text { Total } \\
\text { (all potential range 1-7) }\end{array}$ & $4.29(1.24)$ & $4.21(1.05)$ & -0.08 & 0.77 & $4.32(1.40)$ & $5.58(1.31)$ & 1.26 & $<.001$ \\
\hline
\end{tabular}

\pm all measures higher scores better, *T-test was used

\section{Discussion}

The TAJ program improved self-efficacy to resist smoking, offering an important tool in the armamentarium to decrease smoking amongst young people, particularly when they have asthma symptoms. The need for a program like TAJ is evident in the high prevalence of smoking in adolescents with asthma identified in this study and given the deleterious effects of smoking on individuals with asthma. Almost one in three adolescents smoked despite the presence of asthma symptoms, indicating little effect of anti-smoking programs and highlighting a region needing intense intervention ${ }^{\text {[30, 31] }}$. This is in contrast to countries such as Australia, where tighter smoking regulations have seen the prevalence of smoking decrease from $10 \%$ to $4 \%$ among $12-15$ years old students from 1999 to $2005^{[32]}$. This is particularly important given that the relationship between asthma and smoking is likely to be bidirectional, in which asthma diagnosis can predict smoking onset, and smoking can also increase the risk of developing or worsening asthma ${ }^{[6]}$.

Components of TAJ which were most likely to contribute to effectiveness included the influential role of older peers on younger adolescents. TAJ capitalises on the preference of adolescents to have peer-delivered cessation messages ${ }^{\text {[33] }}$, which may have outweighed the perceived desirability of smoking behavior ${ }^{[34]}$ due to sense of peer acceptance smoking 
may have provided ${ }^{[35,36]}$. This sense of belonging is particularly important for adolescents with asthma, who perceive themselves as different from peers and therefore try to "fit in" with a peer group, even to the extent of adopting risky behaviours ${ }^{[37]}$. Despite the effects smoking may have on exacerbating asthma ${ }^{[10,38]}$, it seems that having asthma was not a strong motivation for students in Jordan to quit smoking ${ }^{[39]}$.

Our study demonstrates that peer influence can be harnessed for positive effects and adolescents can teach their peers and be responsible partners in programs that aim at spreading smoking-related messages and increasing pressure-resistance skills. Peer supporters have been successful in lowering smoking prevalence in high schools in programs such as the A Stop Smoking In Schools Trial (ASSIST) program in the UK ${ }^{[40]}$. However, compared to the approach used in TAJ, the method of teaching in ASSIST was informal, less structured, not classroom based, and not supervised by adults ${ }^{[40]}$. While this approach significantly reduced the prevalence of smoking, more formal and supervised techniques were required for TAJ because it included management of a chronic illness, appropriate use of medications, and emergency treatment plans. The approach used in TAJ was also classroom-based, whereas the method used in ASSIST involved informally passing information to student peers mainly outside classroom ${ }^{[41]}$. These variations highlight the need to match the approach used to train peers to the intent, nature, and complexity of the health messages that need to be disseminated within the peer group culture ${ }^{[42]}$. Furthermore, the TAJ program was based on well-known psychosocial theories and used interactive learning and teaching approach.

TAJ participants demonstrated important improvements in health related quality of life and knowledge of asthma. Previous research has shown a strong relationship between asthma-related knowledge, self-management, and overall quality of life ${ }^{[27,43,44]}$. It appears that students knew more about appropriate asthma management, and therefore improved their management, resulting in enhanced quality of life. However, it is possible that the delivery of a combined program addressing a disease directly affected by smoking may have resulted in the strong effects noted.

The role of gender should not be disregarded as males were seven times more likely to smoke than females. Furthermore, while peers may be important, the presence of family members smoking in the home is also likely to have an impact as our study demonstrated that students who smoked were much more likely to have family who smoked. This area requires further investigation and the potential for TAJ to impact family smoking behaviour is worthy of investigation.

\section{Limitations}

The study included a number of limitations, with the most notable being that smoking behaviour was self-reported and not measured again post intervention. However, studies have found that self-reporting questionnaires, especially those about smoking behaviors, are valid because adolescent smokers provide valid assessments of their own levels of addiction (DiFranza, 2011) ${ }^{[45]}$. Another limitation was that the AKCQ had lower internal consistency reliability than previous reports. Finally, the study was powered for a larger randomized controlled trial and not for the secondary analyses of the intervention effect in smokers, who represent about $30 \%$ of the whole population.

\section{Conclusion}

Our study highlights that a peer-led school based intervention (TAJ) improves asthma self-management behaviours and self-efficacy to resist smoking. The high prevalence of smoking in adolescents with asthma reported in this study should be a strong impetus to implement TAJ within schools in the Middle East. Whether TAJ influences the home environment should be tested in future research given the high prevalence of family smokers reported and the strong association between family smokers and student smoking behaviours. Finally, the TAJ model offers an effective, practical approach to be adopted by community and school healthcare nurse educators and other healthcare professionals nationally and internationally for other health promotion initiatives, such as diabetes and obesity. Similar studies should replicate the current study to with a larger sample size in order to validate the findings. Future studies should also compare the 
effectiveness of peer-led smoking prevention programs for adolescent smokers who have asthma with other relevant interventions to validate the effectiveness of the peer led approach on adolescents' health-related behaviours .

\section{Authors' contributions}

Nihaya Al-sheyab: Study design and development, data collection, data analysis, data interpretation, article drafting and revision.

Robyn Gallagher: Data analysis, data interpretation, article critical revision

Patrick Gallagher: Data analysis, article drafting, technical editing

Smita Shah: Data interpretation, article revision

\section{Acknowledgements and funding}

Nihaya Al-Sheyab undertook this study as a $\mathrm{PhD}$ candidate supported by scholarships from the Jordan University of Science and Technology and the University of Technology, Sydney.

\section{References}

[1] Pierce, J.P. and E. Gilpin, How long will today's new adolescent smoker be addicted to cigarettes? American Journal of Public Health. 1996; 86(2): 253-256. PMid:8633747 http://dx.doi.org/10.2105/AJPH.86.2.253

[2] Research for International Tobacco Control, WHO report on the global tobacco epidemic: the MPOWER package. 2008: World Health Organization.

[3] Belbeisi, A., et al., A surveillance summary of smoking and review of tobacco control in Jordan. Global Health. 2009 ; 5: 18. PMid:19951428 http://dx.doi.org/10.1186/1744-8603-5-18

[4] Khader, Y. and A. Alsadi, Smoking habits among university students in Jordan: prevalence and associated factors. East Mediterr Health J. 2008; 14(4): 897-904. PMid:19166173

[5] Rubinstein, M.L., et al., Smoking-related cue-induced brain activation in adolescent light smokers. Journal of Adolescent Health.2011; 48(1): 7-12. PMid:21185518 http://dx.doi.org/10.1016/j.jadohealth.2010.09.016

[6] Van De Ven, M.O.M., et al., Bidirectionality in the relationship between asthma and smoking in adolescents: a population-based cohort study. Journal of Adolescent Health, 2007. 41(5): 444-454. PMid:17950164 http://dx.doi.org/10.1016/j.jadohealth.2007.05.015

[7] Van De Ven, M.O.M., et al., A longitudinal test of the theory of planned behavior predicting smoking onset among asthmatic and non-asthmatic adolescents. Journal of behavioral medicine, 2007. 30(5): 435-445. PMid:17605099 http://dx.doi.org/10.1007/s10865-007-9119-2

[8] Van De Ven, M.O.M., R.J.J.M. Van Den Eijnden, and R.C.M.E. Engels, Atopic diseases and related risk factors among Dutch adolescents. The European Journal of Public Health, 2006. 16(5): 549-558. PMid:16524943 http://dx.doi.org/10.1093/eurpub/ckl022

[9] Bush, T., et al., Anxiety and depressive disorders are associated with smoking in adolescents with asthma. Journal of Adolescent Health, 2007; 40(5): 425-432. PMid:17448400 http://dx.doi.org/10.1016/j.jadohealth.2006.11.145

[10] de Benedictis, D. and A. Bush, The challenge of asthma in adolescence. Pediatric pulmonology, 2007 ; 42(8): 683-692. PMid:17595039 http://dx.doi.org/10.1002/ppul.20650

[11] Doll, R., et al., Mortality in relation to smoking: 40 years' observations on male British doctors. Bmj, $1994 ; 309(6959)$ : 901. PMid:7755693 http://dx.doi.org/10.1136/bmj.309.6959.901

[12] Chaudhuri, R., et al., Effects of smoking cessation on lung function and airway inflammation in smokers with asthma. American journal of respiratory and critical care medicine, 2006; 174(2): 127-133. PMid:16645173 http://dx.doi.org/10.1164/rccm.200510-15890C

[13] Patten, C.A., et al., Reported willingness among adolescent nonsmokers to help parents, peers, and others to stop smoking. Preventive medicine, 2004; 39(6): 1099-1106. PMid:15539043 http://dx.doi.org/10.1016/j.ypmed.2004.04.020

[14] Carlsen, K.H. and K.C.L. Carlsen, Parental smoking and childhood asthma: clinical implications. Treatments in respiratory medicine, 2005; 4(5): 337-346. PMid:16137191 http://dx.doi.org/10.2165/00151829-200504050-00005

[15] Mellanby, A., J. Rees, and J. Tripp, Peer-led and adult-led school health education: a critical review of available comparative research. Health education research, 2000; 15(5): 533-545. PMid:11184213 http://dx.doi.org/10.1093/her/15.5.533 
[16] Islam, S.M.S. and C.A. Johnson, Influence of known psychosocial smoking risk factors on Egyptian adolescents' cigarette smoking behavior. Health promotion international, 2005; 20(2): 135-145. PMid:15722365 http://dx.doi.org/10.1093/heapro/dah604

[17] Campbell, R., et al., An informal school-based peer-led intervention for smoking prevention in adolescence (ASSIST): a cluster randomised trial. Lancet, 2008; 371(9624): 595. http://dx.doi.org/10.1016/S0140-6736(08)60692-3

[18] Shah, S., et al., Effect of peer led programme for asthma education in adolescents: cluster randomised controlled trial. Bmj, 2001. 322(7286): 583. PMid:11238152 http://dx.doi.org/10.1136/bmj.322.7286.583

[19] Al-sheyab, N., et al., Peer-led Education for Adolescents With Asthma in Jordan: A Cluster-Randomized Controlled Trial. Pediatrics, 2012; 129(1): e106-e112. PMid:22157137 http://dx.doi.org/10.1542/peds.2011-0346

[20] Al-Sheyab, N., et al., Feasibility of a peer-led, school-based asthma education programme for adolescents in Jordan. EMHJ, 2012. 18(5).

[21] Asher, M., et al., International Study of Asthma and Allergies in Childhood (ISAAC): rationale and methods. European Respiratory Journal, 1995; 8(3): 483-491. PMid:7789502 http://dx.doi.org/10.1183/09031936.95.08030483

[22] Lai, C., et al., Comparison of the ISAAC video questionnaire (AVQ 3.0) with the ISAAC written questionnaire for estimating asthma associated with bronchial hyperreactivity. Clinical \& Experimental Allergy, 2006; 27(5): 540-545. http://dx.doi.org/10.1111/j.1365-2222.1997.tb00742.x

[23] Miller, C., et al., Accuracy of Arabic versions of three asthma symptoms questionnaires against the clinical diagnosis of asthma. Journal of Asthma, 2007; 44(1): 29-34. PMid:17365201 http://dx.doi.org/10.1080/02770900601034361

[24] Davis Jr, L.J., et al., Self-administered nicotine-dependence scale (SANDS): Item selection, reliability estimation, and initial validation. Journal of clinical psychology, 1994; 50(6): 918-930. http://dx.doi.org/10.1002/1097-4679(199411)50:6<918::AID-JCLP2270500617>3.0.CO;2-6

[25] Alansari, B., The factor structure of the Arabic version of the Self-Administered Nicotine-Dependence Scale. Social Behavior and Personality: an international journal, 2004; 32(3): 257-264.

[26] Kritikos, V., et al., The validity and reliability of two asthma knowledge questionnaires. Journal of Asthma, 2005; 42(9): 795-801. PMid:16316877 http://dx.doi.org/10.1080/02770900500308627

[27] Juniper, E.F., et al., Measuring quality of life in children with asthma. Quality of Life Research, 1996; 5(1): 35-46. PMid:8901365 http://dx.doi.org/10.1007/BF00435967

[28] Juniper, E., et al., Minimum skills required by children to complete health-related quality of life instruments for asthma: comparison of measurement properties. European Respiratory Journal, 1997; 10(10): 2285-2294. PMid:9387955 http://dx.doi.org/10.1183/09031936.97.10102285

[29] Shah, S., H. Mamoon, and P. Gibson, Peer-led asthma education for adolescents: development and formative evaluation. Health Promotion Journal of Australia: Official Journal of Australian Association of Health Promotion Professionals, 1998 ; 8(3): 177.

[30] Haddad, L.G. and M.Z. Malak, Smoking habits and attitudes towards smoking among university students in Jordan. International journal of nursing studies, 2002; 39(8): 793-802. http://dx.doi.org/10.1016/S0020-7489(02)00016-0

[31] World Health Organization, World health report. Geneva. World Health Organization, 2000.

[32] Branch, D.S., V. White, and J. Hayman, Smoking behaviours of Australian secondary students in 2005. 2006.

[33] Latimer, A.E., et al., Targeted Smoking Cessation Messages for Adolescents. Journal of Adolescent Health, 2011. PMid:22188833

[34] Kobus, K., Peers and adolescent smoking. Addiction, 2003; 98: 37-55. PMid:12752361 http://dx.doi.org/10.1046/j.1360-0443.98.s1.4.x

[35] Gifford-Smith, M.E. and C.A. Brownell, Childhood peer relationships: Social acceptance, friendships, and peer networks. Journal of School Psychology, 2003; 41(4): 235-284. http://dx.doi.org/10.1016/S0022-4405(03)00048-7

[36] Haynie, D.L., Friendship networks and delinquency: The relative nature of peer delinquency. Journal of Quantitative Criminology, 2002; 18(2): 99-134. http://dx.doi.org/10.1023/A:1015227414929

[37] Gettinger, M., Promoting social competence in an era of school reform: A commentary on Gifford-Smith and Brownell. 2003.

[38] Navon, L., B. Fiore, and H. Anderson, Asthma and tobacco: double trouble for Wisconsin adolescents. WMJ-MADISON-, 2005; 104(7): 47.

[39] Zimlichman, E., et al., Smoking habits in adolescents with mild to moderate asthma. Pediatric pulmonology, 2004. 38(3): $193-197$. PMid:15274096 http://dx.doi.org/10.1002/ppul.20080

[40] Audrey, S., et al., Meeting the challenges of implementing process evaluation within randomized controlled trials: the example of ASSIST (A Stop Smoking in Schools Trial). Health education research, 2006; 21(3): p. 366-377. PMid:16740670 http://dx.doi.org/10.1093/her/cyl029

[41] Walker, S.A. and M. Avis, Common reasons why peer education fails. Journal of Adolescence, 1999; $22(4)$ : $573-577$. PMid:10469520 http://dx.doi.org/10.1006/jado.1999.0250 
[42] Story, M., D. Neumark-Sztainer, and S. French, Individual and environmental influences on adolescent eating behaviors. Journal of the American Dietetic Association, 2002; 102(3): S40-S51. http://dx.doi.org/10.1016/S0002-8223(02)90421-9

[43] Abdulwadud, O.A., et al., The relationships between patients' related variables in asthma: implications for asthma management. Respirology, 2001; 6(2): 105-112. PMid:11422889 http://dx.doi.org/10.1046/j.1440-1843.2001.00316.x

[44] Barlow, J., et al., Self-management approaches for people with chronic conditions: a review. Patient education and counseling, 2002; 48(2): p. 177-187. http://dx.doi.org/10.1016/S0738-3991(02)00032-0

[45] R DiFranza, J., et al., The natural history and diagnosis of nicotine addiction. Current Pediatric Reviews, 2011; 7(2): 88-96. http://dx.doi.org/10.2174/157339611795735648 